
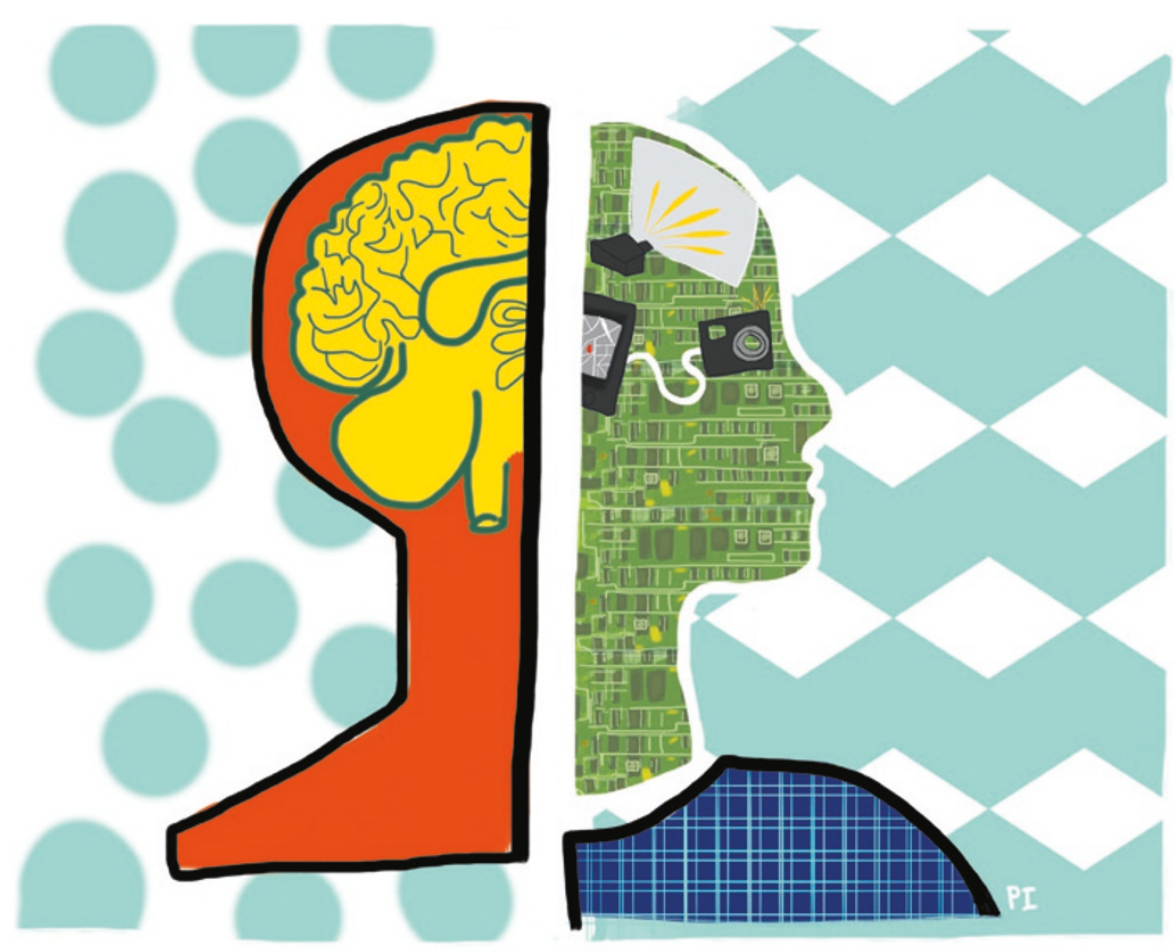

NEUROPHILOSOPHY

\title{
My brain and I
}

\section{Chris Frith reflects on a book that probes the knotty nexus between brain and mind.}

$\mathrm{P}$ atricia Churchland is the doyenne of neurophilosophers. She believes, as I do, that to understand the mind, one must understand the brain, using evidence from neuroscience to refine concepts such as free will. Many philosophers and others are unhappy with this proposal. The problem, Churchland writes, is that deep down we are all dualists. Our conscious selves inhabit the world of ideas; our brains, the world of objects.

So deep is this split that we find it hard to accept an intimate relationship between the mind and brain. In Touching a Nerve, Churchland hopes to help us overcome this aversion and accept the "neural reality of our mental lives". To encourage the general reader, she emphasizes her background as an unsophisticated country girl whose common sense stems from growing up on a farm in an isolated valley in British Columbia, Canada.

She begins by showing us how common sense and neuroscience reveal that there is no need for a soul. We are beginning to have an inkling of the underlying mechanisms that enable thinking, feeling and deciding, such as the precise way in which the anaesthetic procaine removes the sensation of pain. Common sense and neuroscience also tell us that there is no life after death. The light at the

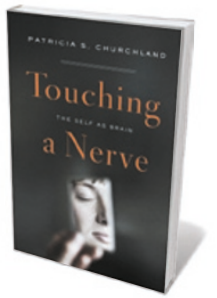

Touching a Nerve: The Self as Brain PATRICIA

CHURCHLAND W. W. Norton: 2013 end of the tunnel associated with near-death experiences is the effect of oxygen starvation on the brain's visual system.

Churchland goes on to discuss morality, aggression, free will and consciousness. But if you were expecting thorough-going interpretations of these concepts in neuroscientific terms, you will be disappointed. She promotes the 'ordinary' meaning of free will - "intending your action, knowing what you are doing, and being of a sound mind". She does not consider the disturbing results of neuroscience research, which suggest that awareness of action - intending and knowing - occur after the action has been selected. We are also told that moral values such as honesty, loyalty and courage depend on learning local conventions and hearing the "stories [that] give you a sense of the right way to act".

I have no quarrel with the idea that upbringing and culture have important roles in determining behaviour, but this does not seem compatible with Churchland's view that "our brains determine everything about who we are and how we experience the world". She also misses the opportunity to present studies that explore the links between brain and culture. There are special processes in the human brain, such as the ability to imitate others with high fidelity, that enable the cumulative development of culture. At the same time, culture moulds the brain and may even drive genetic evolution (see S. E. Fisher \& M. Ridley Science 340, 929-930; 2013). Each human brain is part of a dynamic, interacting system of other brains embedded in culture.

What neuroscience there is in Touching a Nerve is accurate and commendably up to date. There are useful notes associated with each chapter, including primary sources. Yet I became increasingly irritated by the mixture of science and homespun wisdom. Stories about badly behaved schoolgirls and White Leghorn hens did not help my understanding of the basis of aggression and sex. And the referencing is patchy: why does the statement "not every disappointment can be remedied" deserve a reference, whereas the neural basis of Charles Bonnet syndrome and the claim that patients with schizophrenia can tickle themselves do not? As for common sense, I agree with developmental biologist Lewis Wolpert that the important findings of science typically go against it. It is the data supporting the common-sense interpretation that need to be most carefully checked.

Nevertheless, it may well be true that dualism is deeply ingrained in our nature. A recent brain-imaging study revealed that we have two circumscribed brain circuits: one enables us to think about mental causation, such as how unfairness makes us angry; the other enables us to think about physical causality, such as how heat activates pain receptors. These circuits are mutually antagonistic, so we cannot do both at once (see A. I. Jack et al. NeuroImage 66, 385-401; 2013). But if mind-brain dualism is so deeply ingrained, why are the shops full of books such as Touching a Nerve, which show that it is the brain that makes decisions, determines moral values and explains political attitudes?

I can only assume that these are the modern equivalent of Gothic horror stories. We love to be frightened by the thought that we are nothing more than the 1.5 kilograms of sentient meat that is our brain, but we don't really believe it. I don't think Churchland really believes it either.

Chris Frith is emeritus professor of neuropsychology at the Wellcome Trust Centre for Neuroimaging at University College London, and a fellow of All Souls College, Oxford. His books include Making Up the Mind: How the Brain Creates Our Mental World.

e-mail:c.frith@ucl.ac.uk 